\title{
An Empirical Research on the Influencing Factors of Mobile Commerce Diffusion in China
}

\author{
Liwei $\mathrm{Li}$ \\ School of Management, Beijing Union University, Beijing, China \\ liliwei@buu.edu.cn
}

\begin{abstract}
This paper analyzes the factors affecting China's mobile commerce diffusion at the infant stage and taking-off stage using the data of 31 provinces of China in the years of 2009 and 2012 respectively based on the partial least square regression method. The results of the analysis indicate that fixed broadband penetration rate, GDP per capita and internet penetration rate, urbanization level are the top 4 factors at the infant stage of mobile commerce diffusion, while internet penetration rate, $2 G$ mobile penetration rate, income and fixed broadband penetration are the top 4 factors at the taking-off stage of mobile commerce. The findings provide researchers and policy-makers systematic insights into the role of different factors in mobile commerce diffusion at a country level and over time.
\end{abstract}

Keywords: Mobile commerce, Diffusion, PLS, Influencing Factors

\section{Introduction}

Mobile commerce refers to any commerce transaction conducted by using mobile devices via wireless communications. Mobile commerce offers the advantages of ubiquitous access to information, anytime, anywhere. By making business and consumers more effective, mobile commerce is important for both developed countries and developing countries in promoting the national economic development. Mobile has become a cornerstone of the global economy, both as an industry in its own right and as an enabler of opportunities in other sectors (GSMA, 2014). According to the report of World Economic Forum, a 10 percent increase in $3 \mathrm{G}$ penetration increases GDP per capita growth by 0.15 percentage points, and a doubling of mobile data use is associated with an increase in the GDP per capita growth rate of 0.5 percentage points (WEF,2013). The opportunities presented by mobile commerce are reflected by the growth of mobile phones and mobile internet users. By the end of 2013, China had more than 1.4 billion mobile subscribers with an penetration rate $93.5 \%, 400$ million $3 \mathrm{G}$ users with an penetration rate of $33.2 \%$ and 500 million mobile internet users with an annual growth rate of $19.1 \%$. The proportion of those using mobile phones to access the Internet grew rapidly from $74.5 \%$ in 2012 to $81.0 \%$ in 2013 (CNNIC, 2013). Mobile phone has become No. 1 internet access terminal in China. Mobile phones are the main driving force for the growth of mobile internet and mobile commerce in China.

The fast growth of mobile internet users and $3 \mathrm{G}$ subscribers has presented tremendous business opportunity for mobile commerce in China. There is three times the number of mobile subscribers in China as in the US. China presents a market which has huge potential for many mobile commerce service providers. Reports by iiMedia Research stated that China's mobile commerce market reached RMB 47.86 billion with 149 million users in 2012, and estimated that in 2015, the mobile commerce market in China would reach about RMB 253.65 billion with 352 million users.

Although the number of $3 \mathrm{G}$ mobile subscribers is increasing dramatically in China, actual $3 \mathrm{G}$ penetration rate still remains low compared to that of developed countries. By 
the end of 2012, the $3 \mathrm{G}$ penetration rate of US surpassed over $90 \%$ and Japan over $80 \%$, while China just reached 20\%.The aim of this paper is to explore the factors influencing the diffusion of mobile commerce technology in China from the country perspective at different stages of mobile commerce development by a multi-time point approach (i.e., the first point in 2009 and the second point in 2012) through a statistical analysis of 31 provinces. The findings provide researchers and policy-makers systematic insights into the role of different factors in mobile commerce diffusion at a country level and over time especially for developing countries. The rest of the paper is organized as follows. Section 2 presents a brief literature review. Section 3 presents models, methodology and variables. Section 4 reports the empirical results. The last section gives a brief summary and discussion.

\section{Literature Review}

Although many studies have been done in the mobile commerce diffusion area, the literature mainly focuses on the behavioral issues of mobile commerce adoption from the perspective of end users. Factors that influence mobile commerce adoption from the perspective of countries have been less explored. The diffusion of mobile commerce is built on the widespread adoption of mobile telecommunication, thus studies on the diffusion of mobile phones and mobile broadband would provide us with useful insights.

Prior research in mobile phone and mobile broadband diffusion has identified a set of variables that affect the entire diffusion process of mobile commerce. A few factors have been identified as being important, such as income, education level, infrastructure, urbanization rate and price, but a definitive study is lacking due to the difference on sample size and research method.

Based on the Mansfield's model, Luo, et al., (2013) found that investment played a vital role in the starting period of mobile phones, while income, price and urbanization level determined the final development level. Appling choice-based conjoint analysis, Han \& Liu (2012) found that high price of voice service, mobile data service price and $3 \mathrm{G}$ phone price were the main barriers influencing consumer's adoption of $3 \mathrm{G}$ services in China. Based on data for mobile phone subscribers in China for 1986-2007 by using Gompertz model, Liu, et al., (2009) found that fixed line subscribers and price of mobile handsets and services were the determinants for the diffusion rate of mobile phones. Based on the panel data of 31 provinces from1999 to 2012 by using Logistic model, Li, et $a l$., (2013) found that fixed line penetration rate, mobile phone penetration rate, number of operators, price and population density instead of GDP per capita, urbanization rate and innovation were the main factors affecting the diffusion rate of communication industry of China.

Kauffman \& Techatassanasoontorn (2005) tested the effects of country characteristics, digital and analog mobile phone industry characteristics, and regulatory policies on the diffusion rates of digital mobile phones across forty six developed and developing countries, the empirical results showed that GNP per capita, digital mobile phone penetration, the number of digital mobile phone standards, and analog mobile phone penetration were important drivers from the introduction to the early diffusion state. Li \& McQueen (2008) examined the barriers that inhibit the adoption of mobile commerce services in New Zealand, and found that barriers from the supply side instead of customer-related and technological barriers were the major factors influencing the adopting mobile commerce services in New Zealand. Using micro data from 2001, Akiyoshi \& Ono (2008) compared and contrasted the determinants of mobile versus computer-based internet in Japan, findings showed that mobile internet access, as compared to computer access, was determined less by demographics, socioeconomic status, and technological readiness. Through a regression analysis of 106 observations, Lee, et al.,(2007 found that multiple standardization policy, 
lower level of $1 \mathrm{G}$ and $2 \mathrm{G}$ penetration, and a higher level of income contribute to the diffusion of 3G mobile. Employing a logistic diffusion model, Lee, et al., (2011) analyzed the factors that influence the diffusion of fixed and mobile broadband, and found that for mobile broadband, multiple standardization policy and population density were the main factors of the initial diffusion of mobile broadband services.

The above literature review suggests that there are very few studies on mobile commerce diffusion in China-the largest mobile commerce market in the world. Besides, current research only examined variables that influence the entire diffusion process, and lack the analysis on the relative importance of different factors at different stages of mobile commerce development. Furthermore, most previous studies have been limited in scope considering only a small set of variables. This study tries to fill in the gaps with a comprehensive econometric analysis of the determinants of China's mobile commerce diffusion that spans both infant stage and taking-off stage and includes a wide-range of economic, education level, infrastructure and user factors.

\section{Model, Variables and Methodology}

\subsection{Model and Variables}

Based on the literature review, our candidate variables include economic variables, urbanization rate, education level variables, infrastructure variables, user indicators, price and innovation variables, as shown in Table 1.This study has 7 dimensions with 13 independent variables and 1 dependent variable.

As data related to mobile commerce is lacking, we choose $3 \mathrm{G}$ penetration rate as the surrogate measure of mobile commerce diffusion rate. $3 \mathrm{G}$ penetration rate refers to the number of $3 \mathrm{G}$ users per 100 people. Diffusion of mobile commerce is based on the widespread adoption of 3G technology and smart phones. China approved issuing 3G licenses to mobile operators in the end of 2008.WCDMA, CDMA 2000 and TD SCDMA are the three main standards for $3 \mathrm{G}$ wireless technologies in China. WCDMA was issued to China Unicom, CDMA 2000 was issued to China Telecom and TD SCDMA proposed by China was issued to China Mobile.

The model is specified as follows:

$Y=\alpha+\sum_{i=1}^{13} \beta i X i+\mu$

In this equation $\alpha$ is the regression coefficient for the intercept and the $\beta i$ values are the regression coefficients.

Table 1. Variable and Measurement

\begin{tabular}{llll}
\hline Variable type & \multicolumn{1}{c}{ Dimension } & \multicolumn{1}{c}{ Measurement } & Symbo \\
& & & 1 \\
\hline Dependent & diffusion rate & 3G penetration rate & $Y$ \\
Independent & User base & 2G penetration rate & $X_{1}$ \\
& & Internet penetration rate & $X_{2}$ \\
& & Fixed broadband penetration rate & $X_{3}$ \\
& Urbanization & Urban population proportion & $X_{4}$ \\
& rate & GDP per captia & $X_{5}$ \\
& Income & Disposable income per captia & $X_{6}$ \\
& & Schooling yeas & $X_{7}$ \\
& Education level & $X_{8}$ \\
& Innovation & Proportion with secondary or above education & $X_{9}$ \\
& Infrastructure & Patent applications per ten thousand people & $X_{10}$ \\
\hline
\end{tabular}




\begin{tabular}{cll}
\hline & Cable length per captia/km & $X_{11}$ \\
& telecoms investment per captia & $X_{12}$ \\
Price & Communication price index & $X_{13}$ \\
Change & & \\
\hline
\end{tabular}

User variables are measured by $2 \mathrm{G}$ penetration rate, internet penetration rate and fixed broad penetration rate. Mobile phone users and internet users provide the basis for mobile commerce use. Regions that already have high mobile phone and internet penetration rates have seen users embrace broadband services more readily (Lee, 2007).

Chew (2006) found that the level of E-Commerce adoption is a determinant of the adoption of Mobile commerce in United States. We assume that the proportion of related users ( $2 \mathrm{G}$ mobile phone users and internet users) is a determinant of mobile commerce diffusion.

Urbanization rate is measured by the share of urban population. Some early studies examining the relationship between mobile diffusion and share of urban population find no significant correlation between the two variables (Gruber, 2001; Lee, et al., 2007). On the contrary, some recent study has found that there is significant negative correlation between rural population rate and mobile adoption rate (Luo, et al., 2013; Li, et al., 2013), as shown in Figure 1. City has more mobile network coverage and good information infrastructure required by mobile commerce. We assume that the urbanization level is a determinant of mobile commerce diffusion.

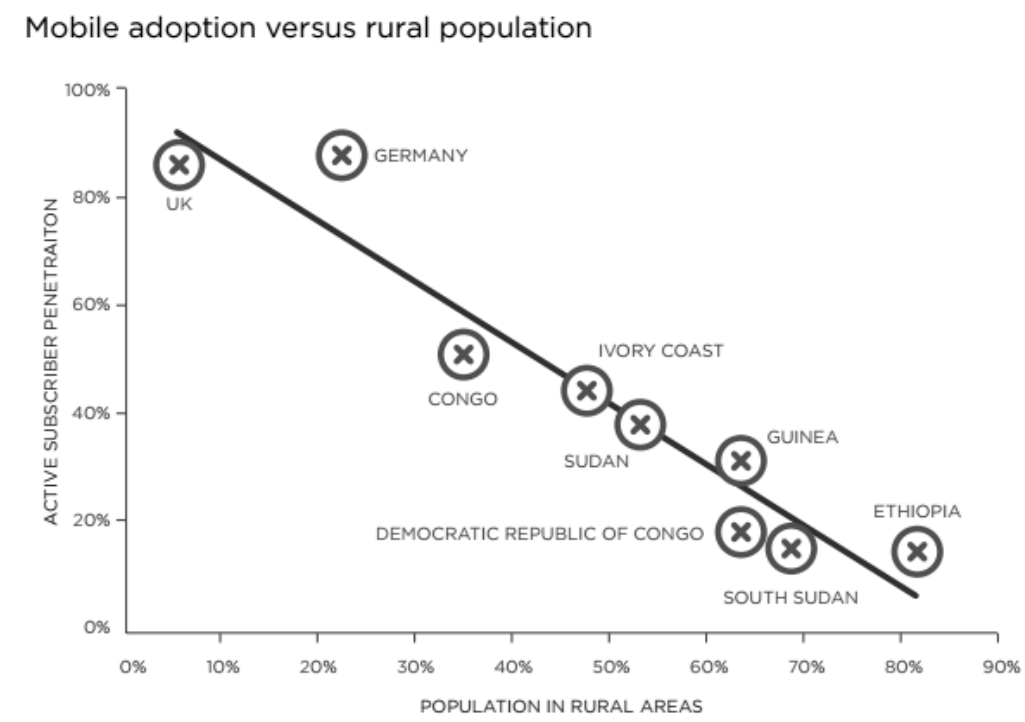

Source: GSMA Intelligence, the Mobile Economy 2014.

Figure 1. Mobile Adoption and Rural Population

Income variables are measure by GDP per capita and disposable income per captia. Many previous studies had found that income was the major contributing variable to mobile diffusion (Andonova, 2006; Lee, et al., 2007). Early adopters tend to have higher socio-economic status (Rogers, 2003). The global digital divide is mainly accounted for by income differentials. We assume that the income level is a determinant of mobile commerce diffusion.

Education level variables, namely human capital variables are measured by schooling years and proportion with secondary or above education. The use of mobile commerce technology requires users having certain levels of education. Those who have higher educational level are more likely to adopt mobile commerce 
(Chong, 2013). We assume that the education level is a determinant of mobile commerce diffusion.

Innovation variable is measured by patent applications per ten thousand people. Many studies of micro perspective from consumers indicated that personal innovativeness was significantly correlated with mobile commerce adoption (Park, 2007; Chong, et al., 2013). Similarly, at the macro level, regions with high innovation capacity would be more likely to adopt mobile commerce. We assume that the innovation capacity is a determinant of mobile commerce diffusion.

Infrastructure variables are measured by mobile telephone exchange capacity per captia, cable length per captia/km and telecoms investment per captia. Adoption and diffusion of mobile commerce are directly built on the telecommunication infrastructure. Some regions might be more prepared than others to adopt mobile commerce because of their existing ICT infrastructure development. We assume that infrastructure is a determinant of mobile commerce diffusion.

This study use communication price index to measure the changes in price level of mobile equipment and service. According to the law of demand, as the price of a good falls, the quantity demanded rises. Li, et al., (2013) found that decreasing telecommunication price had a significantly positive effect on the mobile communication technology diffusion rate of China. We assume that price is negatively correlated with mobile commerce diffusion.

\subsection{Data}

The sample of this study is 31 provinces of China. Data on mobile phone use and telecommunications infrastructure are from statistical bulletin of communication industry published by ministry of Industry and Information Technology in China. The primary source for data on demographics, income, and other variables is China Statistical Yearbook (2010 and 2013).Data on internet use and broadband are from annual Statistical Report on internet Development in China published by China Internet Network Information Center (CNNIC) in 2009 and 2012. Some indicators including schooling years, mobile telephone exchange capacity per captia, cable length per captia/km, telecoms investment per captia and patent applications per ten thousand people are calculated from the original data.

\subsection{Methodology}

For data analysis, this study employed partial least squares regression (PLS regression) method with SIMCA-P+ 11 version. PLS regression is a statistical method that generalizes and combines characteristics of principal component analysis and multiple regression. PLS regression finds a linear regression model by projecting the predicted variables and the observable variables to a new space. PLS regression is particularly suited when there is multicollinearity among variables and/or the number of independent variables is comparable to or greater than sample size (Wang, 1999). PLS regression is becoming a tool of choice in the social sciences as a multivariate technique.

To explore the relationships among variables and assess multicollinearity among independent variables, Pearson correlation coefficients and variance inflation factors were calculated by SPSS19.0 using the data of 2012. As shown in Table 2, the Pearson correlation coefficients among variables revealed the strongest correlations among variables. As shown in Table 3, most of the variance inflation factors (VIF) in the regression models were more than the usual cutoff level of 10.0. The result of year 2009 is similar too. Hence, multicollinearity problems were found to be serious. In this case the solution of classical least squares problem is unstable and unreliable, while PLS approach leads to stable, correct and highly predictive models even for correlated descriptors. 
Table 2. Pearson Correlation Coefficients

\begin{tabular}{|c|c|c|c|c|c|c|c|c|c|c|c|c|c|c|}
\hline & $Y$ & $X_{1}$ & $X_{2}$ & $X_{3}$ & $X_{4}$ & $X_{5}$ & $X_{6}$ & $X_{7}$ & $X_{8}$ & $X_{9}$ & $X_{10}$ & $X_{11}$ & $X_{12}$ & $X_{13}$ \\
\hline & 1.0 & 0.89 & 0.92 & 0.71 & 0.84 & 0.80 & 0.84 & 0.68 & 0.57 & 0.51 & 0.49 & 0.61 & 0.52 & -0.46 \\
\hline$Y$ & 0 & & & & & & & & & & & & & \\
\hline$X_{1}$ & & 1.00 & 0.90 & 0.57 & 0.78 & 0.78 & 0.75 & 0.53 & 0.42 & 0.33 & 0.36 & 0.47 & 0.47 & -0.47 \\
\hline$X_{2}$ & & & 1.00 & 0.78 & 0.92 & 0.85 & 0.87 & 0.66 & 0.58 & 0.44 & 0.42 & 0.62 & 0.41 & -0.47 \\
\hline$X_{3}$ & & & & 1.00 & 0.80 & 0.71 & 0.91 & 0.56 & 0.51 & 0.32 & 0.39 & 0.79 & 0.27 & -0.22 \\
\hline$X_{4}$ & & & & & 1.00 & 0.74 & 0.84 & 0.65 & 0.62 & 0.47 & 0.39 & 0.55 & 0.27 & -0.27 \\
\hline$X_{5}$ & & & & & & 1.00 & 0.87 & 0.75 & 0.66 & 0.35 & 0.36 & 0.65 & 0.40 & -0.50 \\
\hline$X_{6}$ & & & & & & & 1.00 & 0.64 & 0.55 & 0.38 & 0.41 & 0.80 & 0.38 & -0.31 \\
\hline$X_{7}$ & & & & & & & & 1.00 & 0.96 & 0.42 & 0.41 & 0.49 & 0.09 & -0.43 \\
\hline$X_{8}$ & & & & & & & & & 1.00 & 0.42 & 0.35 & 0.46 & -0.04 & -0.32 \\
\hline$X_{9}$ & & & & & & & & & & 1.00 & 0.33 & 0.06 & 0.41 & -0.25 \\
\hline$X_{1}$ & & & & & & & & & & & 1.00 & 0.39 & 0.60 & -0.26 \\
\hline$\stackrel{0}{\boldsymbol{X}_{1}}$ & & & & & & & & & & & & 1.00 & 0.21 & -0.23 \\
\hline$\stackrel{1}{\boldsymbol{X}_{1}}$ & & & & & & & & & & & & & 1.00 & -0.26 \\
\hline$\stackrel{2}{\boldsymbol{X}_{1}}$ & & & & & & & & & & & & & & 1.00 \\
\hline
\end{tabular}

Table 3. Variance Inflation Factors (VIF)

\begin{tabular}{|c|c|c|c|c|c|c|c|c|c|c|c|c|c|}
\hline & $X_{1}$ & $X_{2}$ & $X_{3}$ & $X_{4}$ & $X_{5}$ & $X_{6}$ & $X_{7}$ & $X_{8}$ & $X_{9}$ & $X_{10}$ & $X_{11}$ & $X_{12}$ & $X_{13}$ \\
\hline VIF & 10.369 & 36.869 & 11.358 & 25.644 & 17.941 & 45.159 & 41.677 & 52.761 & 3.593 & 2.729 & 8.938 & 4.672 & 2.085 \\
\hline
\end{tabular}

Unlike most cross-sectional analyses that take place at a single point in time, this paper involved a series of data collections and measurements at multiple points in time. Phase I of the data collection occurred in 2009. It represents the early stage of mobile commerce diffusion. Phase II of the data collection occurred in 2012. It represents the taking-off stage of mobile commerce diffusion in China.

This study chose year 2009 as the representation of infant stage of mobile commerce diffusion, because China approved issuing $3 \mathrm{G}$ licenses to mobile operators in the end of 2008. The mobile industry of China has scaled dramatically over the last five years. $3 \mathrm{G}$ penetration rate had increased from 1.6 percent in 2009 to over 30\% in 2013 as shown in Table 4.According to the theory of innovation diffusion theory, the adoption rate of the innovation should reach a critical mass in order to self-sustain. Diffusion of existing technologies including mobile phones has been measured in $\mathrm{S}$ curves, as the early adopters select the technology first, followed by the majority, until a technology or innovation is common (Rogers,2003). The S-shaped diffusion curve "takes off" at about 10 to 20 percent adoption generally (Rogers, 2003). By the end of 2012, the 3G penetration rate was $20.9 \%$, which had reached the critical mass of taking-off stage, thus this study chose year 2012 as the representation of taking-off stage for mobile commerce diffusion. This temporal approach to observe the transformation of the influence of different factors over time provides a better basis for causal inference than a single cross-sectional study does (Jupp, 2006).

Table 4. Mobile Phone And 3G Penetration Rate in China from 2009 To 2013

\begin{tabular}{lccccc}
\hline & 2009 & 2010 & 2011 & 2012 & 2013 \\
\hline Mobile phone penetration rate & $56.27 \%$ & $64.36 \%$ & $73.55 \%$ & $82.50 \%$ & $90.8 \%$ \\
3G penetration rate & $1.6 \%$ & $5.5 \%$ & $13 \%$ & $20.9 \%$ & $32.7 \%$ \\
\hline
\end{tabular}

Data Source: Ministry of Industry and Information Technology, P.R. China 


\section{Empirical results}

\subsection{Phase I: 2009}

PLS regression searches for a set of components that performs a simultaneous decomposition of $\mathrm{X}$ and $\mathrm{Y}$ with the constraint that these components explain as much as possible of the covariance between $\mathrm{X}$ and $\mathrm{Y}$. One component is selected automatically by SIMCA-P+11 according to the test of cross-validation, explaining $84.9 \%$ of the variance of $\mathrm{Y}$ with a predictive ability of $79 \%$, which indicates an excellent model. As shown in Figure 2, if choosing two components, the value of cross-validation test is -0.063977 , which is lower than the critical value of 0.0975 , and it means that we should keep one component to fit the PLS model.

\begin{tabular}{|l|l|r|r|r|r|r|}
\hline Var ID (Y) & & R2VY & R2VY(cum) & Q2VY & Q2 limit & Q2VY(cum) \\
\hline Total & Comp 1 & 0.849308 & 0.849308 & 0.790449 & 0.05 & 0.790449 \\
\hline & Comp 2 & 0.0117501 & 0.861059 & -0.0639777 & 0.05 & 0.777043 \\
\hline
\end{tabular}

Figure 2. Model Overview List-2009

Table 5 shows the coefficients of PLS regressions using the data of 2009.As we can see, except for price, all the other variables are positive correlated with mobile diffusion. The results means that lower price, more users on $2 \mathrm{G}$ and internet, higher urbanization rate, higher income and education level, good infrastructure and innovation capability are the contributors of mobile diffusion in the infant stage. It is worth noting that the positive coefficients of $2 \mathrm{G}$ penetration and fixed broadband penetration suggests $3 \mathrm{G}$ mobile is a complement of $2 \mathrm{G}$ mobile, and mobile broadband is a complement of fixed broadband in the initial stage.

Table 5. Pls Regression Coefficient-2009

\begin{tabular}{cr}
\hline Variables & Coefficient \\
\hline Constant & 1.026 \\
$\mathrm{X}_{1}$ & 0.088 \\
$\mathrm{X}_{2}$ & 0.093 \\
$\mathrm{X}_{3}$ & 0.095 \\
$\mathrm{X}_{4}$ & 0.090 \\
$\mathrm{X}_{5}$ & 0.094 \\
$\mathrm{X}_{6}$ & 0.089 \\
$\mathrm{X}_{7}$ & 0.074 \\
$\mathrm{X}_{8}$ & 0.060 \\
$\mathrm{X}_{9}$ & 0.089 \\
$\mathrm{X}_{10}$ & 0.084 \\
$\mathrm{X}_{11}$ & 0.075 \\
$\mathrm{X}_{12}$ & 0.085 \\
$\mathrm{X}_{13}$ & -0.032 \\
\hline
\end{tabular}

To examine the relative importance of each factor to the dependent variable, variable importance in the projection (VIP) is used in PLS regression. The bigger of the VIP value (over 1) is, the more important contribution to dependent variable is. Figure 3 is the VIP plot generated by SIMCA-P+. As we can see that fixed broadband penetration $\operatorname{rate}\left(\mathrm{X}_{3}\right)$, GDP per capita $\left(\mathrm{X}_{5}\right)$ and internet penetration $\operatorname{rate}\left(\mathrm{X}_{2}\right)$, urbanization level $\left(\mathrm{X}_{4}\right)$, disposable income per captia $\left(\mathrm{X}_{6}\right)$ and patent applications per ten thousand people $\left(\mathrm{X}_{9}\right), 2 \mathrm{G}$ penetration $\operatorname{rate}\left(\mathrm{X}_{1}\right)$, internet penetration $\operatorname{rate}\left(\mathrm{X}_{12}\right)$ and mobile telephone exchange 
capacity per captia $\left(\mathrm{X}_{10}\right)$ are the significant factors at the infant stage of mobile commerce, while the contribution of cable length per captia/ $\mathrm{km}\left(\mathrm{X}_{11}\right)$, human capital $\left(\mathrm{X}_{7}, \mathrm{X}_{8}\right)$ and price $\left(\mathrm{X}_{13}\right)$ are relatively weaker.

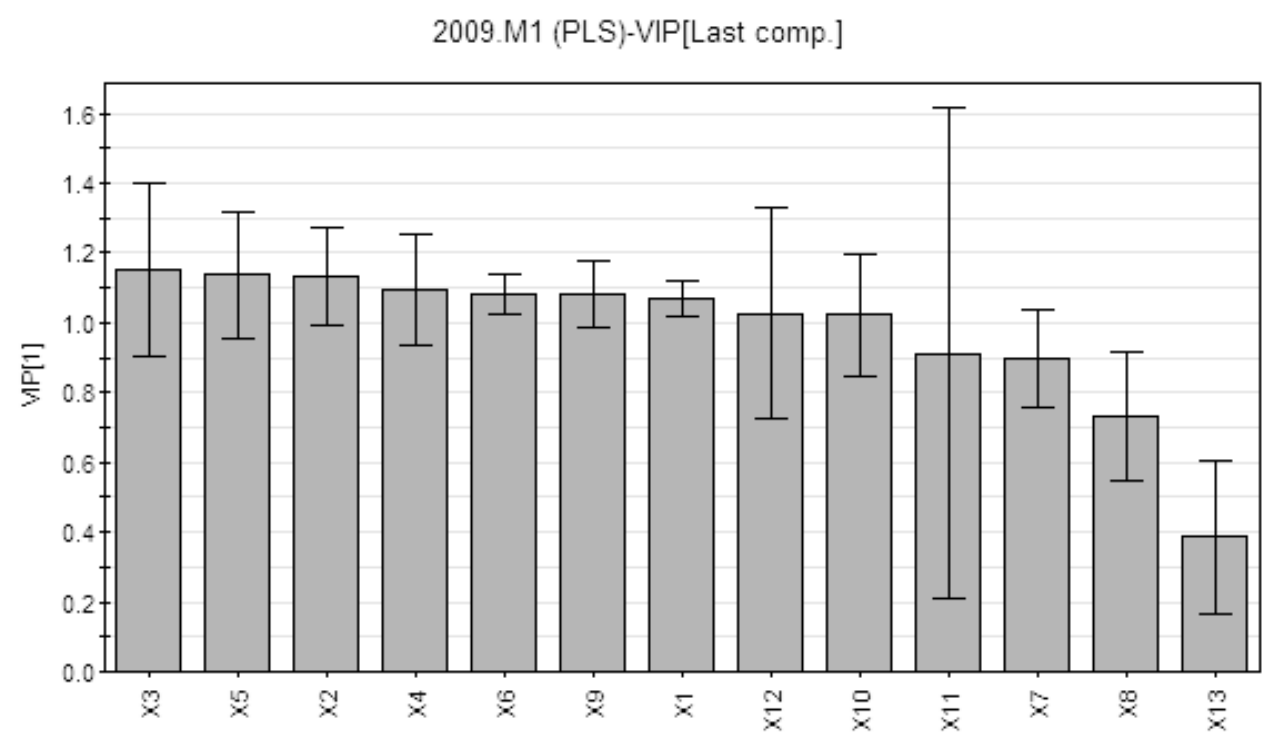

Figure 3. VIP Plot-2009

\subsection{Phase II: 2012}

One component is selected automatically by SIMCA-P+11 according to the test of cross-validation, explaining $85.7 \%$ of the variance of $\mathrm{Y}$ with a predictive ability of $80.4 \%$, which indicates an excellent model. As shown in Figure 4, if choosing two components, the value of cross-validation test is -0.0374948 , which is lower than the critical value of 0.0975 , and it means that we should keep one component to fit the PLS model.

\begin{tabular}{|l|l|r|r|r|r|r|}
\hline Var ID (y) & & R2VY & R2VY(cum) & Q2VY & Q2 limit & Q2VY(cum) \\
\hline Total & Comp 1 & 0.857624 & 0.857624 & 0.804086 & 0.05 & 0.804086 \\
\hline & Comp 2 & 0.0398398 & 0.897464 & -0.0374948 & 0.05 & 0.79674 \\
\hline
\end{tabular}

Figure 4. Model overview list-2012

Table 6 shows the coefficients of PLS regressions using the data of 2012.Similar with the results in 2009, xcept for price, all the other variables are positive correlated with mobile diffusion. The coefficients of $2 \mathrm{G}$ penetration and fixed broadband penetration are still positive, which indicates that $3 \mathrm{G}$ mobile is also a complement of $2 \mathrm{G}$ mobile, and mobile broadband is a complement of fixed broadband in the taking-off stage too. This result is same with the study of Lee (2011), et al.,, who finds that in many OECD countries, mobile broadband service is a complement to fixed broadband service in the initial deployment of broadband. China is still in the early stages of broadband deployment, thus mobile broadband penetration rate is growing rapidly in line with fixed broadband. 
Table 6. PIs Regression Coefficient-2012

\begin{tabular}{cr}
\hline Variables & Coefficient \\
\hline Constant & 2.667 \\
$\mathrm{X}_{1}$ & 0.117 \\
$\mathrm{X}_{2}$ & 0.121 \\
$\mathrm{X}_{3}$ & 0.111 \\
$\mathrm{X}_{4}$ & 0.107 \\
$\mathrm{X}_{5}$ & 0.106 \\
$\mathrm{X}_{6}$ & 0.111 \\
$\mathrm{X}_{7}$ & 0.090 \\
$\mathrm{X}_{8}$ & 0.076 \\
$\mathrm{X}_{9}$ & 0.067 \\
$\mathrm{X}_{10}$ & 0.065 \\
$\mathrm{X}_{11}$ & 0.080 \\
$\mathrm{X}_{12}$ & 0.068 \\
$\mathrm{X}_{13}$ & -0.061 \\
\hline
\end{tabular}

Figure 5 is the VIP plot generated by SIMCA-P+ using the data of 2012.As we can see that internet penetration $\operatorname{rate}\left(\mathrm{X}_{2}\right), 2 \mathrm{G}$ penetration $\operatorname{rate}\left(\mathrm{X}_{1}\right)$, and disposable income per captia $\left(\mathrm{X}_{6}\right)$, fixed broadband penetration $\operatorname{rate}\left(\mathrm{X}_{3}\right)$, urbanization level $\left(\mathrm{X}_{4}\right)$ and GDP per capita $\left(\mathrm{X}_{5}\right)$ are the significant factors at the taking-off stage of mobile commerce diffusion, while the contribution of human capital $\left(\mathrm{X}_{7}, \mathrm{X}_{8}\right)$, cable length per captia/km( $\left.\mathrm{X}_{11}\right)$, internet penetration rate $\left(X_{12}\right)$, patent applications per ten thousand people $\left(X_{9}\right)$, mobile telephone exchange capacity per captia $\left(\mathrm{X}_{10}\right)$ and price $\left(\mathrm{X}_{13}\right)$ are relatively weaker.

2012.M1 (PLS)-VIP

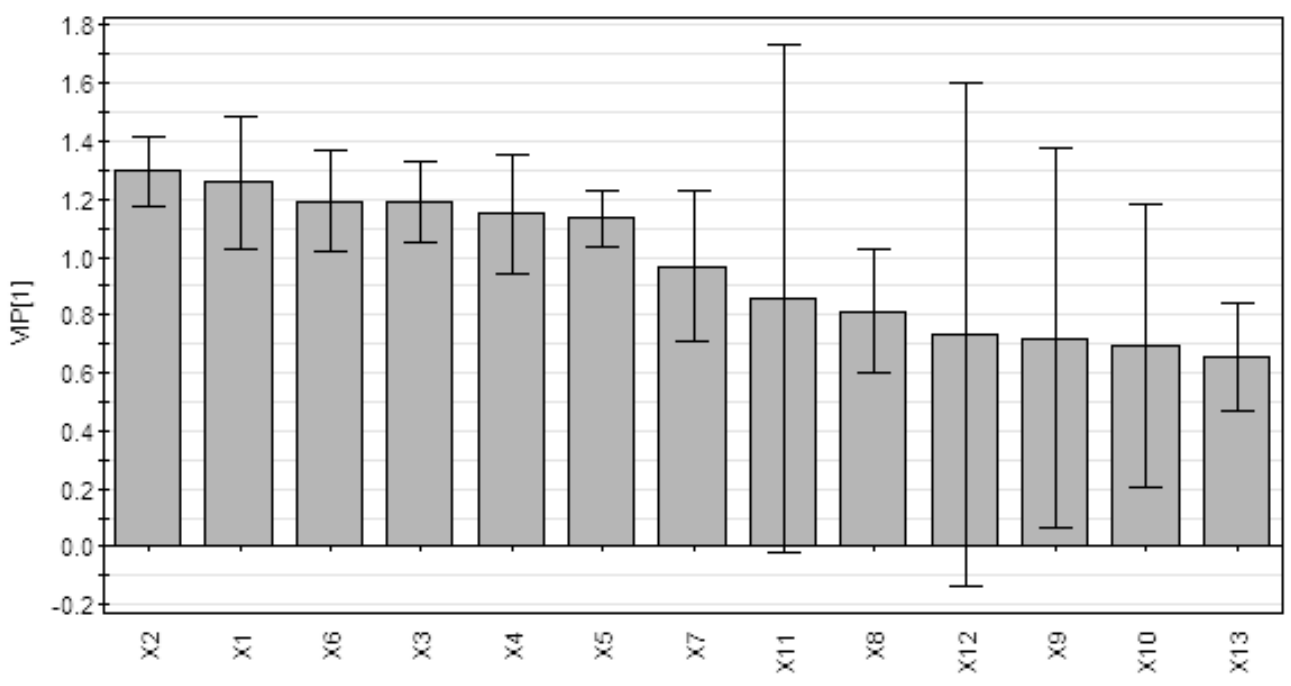

Figure 5. VIP Plot-2012

\subsection{Comparison}

The number of significant factors in the early stage is more than that in the taking-off stage. The similarities between two stages are that more stock users of internet and mobile phone, higher levels of income, higher urbanization rate are both important factors. The differences between two stages lies in that innovation capacity and telecommunication infrastructure are more important in the early stage of mobile commerce diffusion. 
From the difference of the regression coefficients, we can see the changing trends on the importance of different influencing factors. The bigger coefficients of stock users, urbanization rate, income and human capital in phase II imply these factors are becoming increasingly important, while the smaller coefficients of innovation capacity and infrastructure in phase II imply their reducing importance.

\section{Conclusions}

This paper analyzes the factors affecting China's mobile commerce diffusion over time using the data of 31 provinces of China in the years of 2009 and 2012 respectively based on the partial least square regression method. The study includes a wide-range of economic, education, infrastructure and user factors.

The results of the analysis indicate that more stock users of internet and mobile phone, higher levels of income, higher urbanization rate, stronger innovation capacity and better telecommunication infrastructure are the driving factors of mobile commerce diffusion at the infant stage, while more stock users of internet and mobile phone, higher levels of income and higher urbanization rate are the driving factors of mobile commerce diffusion at the taking-off stage. More specifically, fixed broadband penetration rate, GDP per capita and internet penetration rate, urbanization level are the top 4 factors at the infant stage of mobile commerce, while internet penetration rate, $2 \mathrm{G}$ mobile penetration rate, income and fixed broadband penetration are the top 4 factors at the taking-off stage.

The findings provide researchers and policy-makers systematic insights into the role of different factors in mobile commerce diffusion over time at a country level especially for developing countries.

\section{Acknowledgements}

This study is funded by "New Start" Academic Research Projects of Beijing Union University (No.Sk10201409).

\section{References}

[1] "GSMA, Economy, http://www.gsmamobileeconomy.com/GSMA\%20Mobile\%20Economy\%202013.pdf.

[2] "World Economic Forum. Global Information Technology Report", http://www.weforum.org/reports/global-information-technology-report-2013.

[3] "China Internet Network Information Center", $33^{\text {th }}$ Statistical Report on Internet Development in China, http://www1.cnnic.cn/IDR/ReportDownloads/201404/U020140417607531610855.pdf.

[4] "iiMedia Research", Annual Report of China's M-commerce Market, (2012), http://www.iimedia.cn/36543.html.

[5] Y. Luo, L. Luo, C. Liu and Y. Chen, "What Factors Influence the Diffusion of the Mobile Communications Industry: a Case Study from China. The World Economy, vol. 36, no. 12, (2013).

[6] Y. Han and W. Liu, "Factors Influencing the Adoption of Third-Generation Mobile Services by Consumer-Evidence from Chongqing Mobile Communications Market”, Management Review, vol. 24, no. 8 , (2012).

[7] X. Liu, F. Wu and W. Zhu, "A Study on the Drivers of Innovation Diffusion of Mobile Telephony in China and Forecasting Mode", China Soft Science, vol. 6, (2009).

[8] Z. Li, M. Wu and S. Yang, "An Empirical Study of Mobile Communication Technology DiffusionBased on the Data from 1990 to 2012 in China", Modern Economic Science, vol. 35, no. 6, (2013).

[9] R. J. Kauffman and A. A. Techatassanasoontorn, "International Diffusion of Digital Mobile Technology: a Coupled-Hazard State-Based Approach”, Information Technology and Management, vol. 6 , no. 2, (2005).

[10] W. Li and R. J. McQueen, "Barriers to Mobile Commerce Adoption: an Analysis Framework for a Country-level Perspective”, International Journal of Mobile Communications, vol. 6, no. 2, (2008).

[11] M. Akiyoshi and H. Ono, "The Diffusion of Mobile Internet in Japan”, The Information Society, vol. 24, no. $5,(\mathbf{2 0 0 8})$.

[12] S. Lee, S. M. Chan-Olmsted and H. Kim, "the Deployment of Third-Generation Mobile Services: a Multinational Analysis of Contributing Factors", Association for Education in Journalism and Mass Communication Annual Convention, (2007) August 9, Washington, DC, USA. 
[13] S. Lee, M. Marc and S. Lee, "An Empirical Analysis of Fixed and Mobile Broadband Diffusion", Information Economics and Policy, vol. 23, no. 3, (2011).

[14] A. A. Chew, "The adoption of M-Commerce in the United States California State University", Long Beach, CA, (2006).

[15] H. Gruber, "Competition and innovation: The diffusion of mobile telecommunications in Central and Eastern Europe", Information Economics and Policy, vol. 13, no. 1, (2001).

[16] V. Andonova, "Mobile phones: the Internet and the institutional environment", Telecommunications Policy, vol. 30, (2006).

[17] A. Y. L. Chong, "Predicting m-commerce adoption determinants: A neural network approach", Expert Systems with Applications, vol. 40, no. 2, (2013).

[18] J. K. Park, S. Yang and X. Lehto, "Adoption of Mobile Technologies for Chinese Consumers", Journal of Electronic Commerce Research, vol. 8, no. 3, (2007).

[19] E. M. Rogers, "Diffusion of Innovations", Free Press, New York, (2003).

[20] V. Jupp, "the Sage Dictionary of Social Research Methods", Sage Publications, London, (2006).

[21] H. Wang, "Partial Least Square Regression-Method and Applications", National Defense Industry Press, Beijing, (1999).

\section{Author}

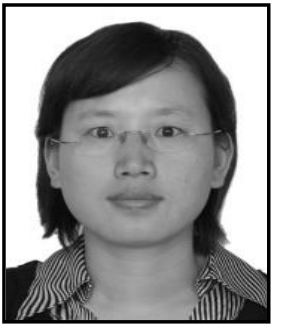

Liwei Li, Lecturer, Department of Information Management and E-commerce, Management School of Beijing Union University, China;

Ph.D. Candidate of Chinese Academy of Social Sciences;

Research interest includes m-commerce and e-commerce. 
International Journal of $u-$ and e- Service, Science and Technology Vol.8, No. 6 (2015) 